This item was submitted to Loughborough's Research Repository by the author.

Items in Figshare are protected by copyright, with all rights reserved, unless otherwise indicated.

\title{
How do technique and coordination change during learning of a whole-body task: Application to the upstart in gymnastics
}

PLEASE CITE THE PUBLISHED VERSION

https://doi.org/10.1080/02640414.2019.1634413

\section{PUBLISHER}

(C) Taylor \& Francis

\section{VERSION}

AM (Accepted Manuscript)

\section{PUBLISHER STATEMENT}

This is an Accepted Manuscript of an article published by Taylor \& Francis in Journal of Sports Sciences on 21 Jun 2019, available online: https://doi.org/10.1080/02640414.2019.1634413

\section{LICENCE}

CC BY-NC-ND 4.0

\section{REPOSITORY RECORD}

Hiley, Michael J., Nicole Schmid, and Maurice R. Yeadon. 2019. "How Do Technique and Coordination Change During Learning of a Whole-body Task: Application to the Upstart in Gymnastics". figshare. https://hdl.handle.net/2134/38247. 
Journal of Sports Sciences ${ }^{* *},{ }^{* * *-* * * *}, 2019$

\title{
How do technique and coordination change during learning of a whole-body task: Application to the upstart in gymnastics
}

\author{
${ }^{1}$ Michael J Hiley, ${ }^{2}$ Nicole Schmid and ${ }^{1}$ Maurice R Yeadon
}

${ }^{1}$ School of Sport, Exercise and Health Sciences, Loughborough University, Leicestershire, LE11 3TU, UK

${ }^{2}$ Department of Health Sciences and Technology, ETH Zurich, Switzerland

\begin{abstract}
When learning swinging skills on a bar there has been conflicting advice in the research literature regarding whether to coach the "gold standard" technique to novices. The present study aimed to determine how technique (joint angle time histories) and (inter-limb) coordination changed as novice gymnasts learned a fundamental gymnastics skill (the upstart). It was hypothesised that both technique and coordination would become more like an expert as learning progressed. Eight novice gymnasts, unable to perform an upstart, underwent four months of training, with the number of successful upstarts out of 10 recorded at the start and then every month subsequently. In the first and last sessions motion capture was used to determine joint kinematics. Root mean squared differences for the joint angle time histories and continuous relative phase at the shoulder and hip were calculated between the novices and an expert gymnast. As training progressed technique and coordination became more like the expert gymnast. The more successful novices were better able to time their actions within the swing than the less successful novices. Gymnastics coaches teach towards a "gold standard" technique since being successful at the skill is not the only goal, as considerations for future skill development are made.
\end{abstract}

Keywords: motor learning, skill acquisition, inter-limb coordination, coaching

\section{INTRODUCTION}

The upstart is a fundamental skill in gymnastics, requiring co-ordination of the body segments with the swing about the bar, and is used to transfer the gymnast from a swing beneath the bar to a position of support above the bar (Figure 1). The skill is employed by elite and beginner gymnasts in men's and women's artistic gymnastics on various pieces of apparatus which incorporate swinging skills. The basic technique of an upstart comprises a swinging phase to a position of body extension (Figure $1 \mathrm{~A}$ B) followed by a "kip" phase (Figure $1 \mathrm{C}-\mathrm{D}$ ) to raise the centre of mass to the bar. To receive no deductions from the judges (Fédération Internationale de Gymnastique, 2017) the gymnast must show good extension at the front of the swing and perform the whole skill fluently with straight arms and legs.
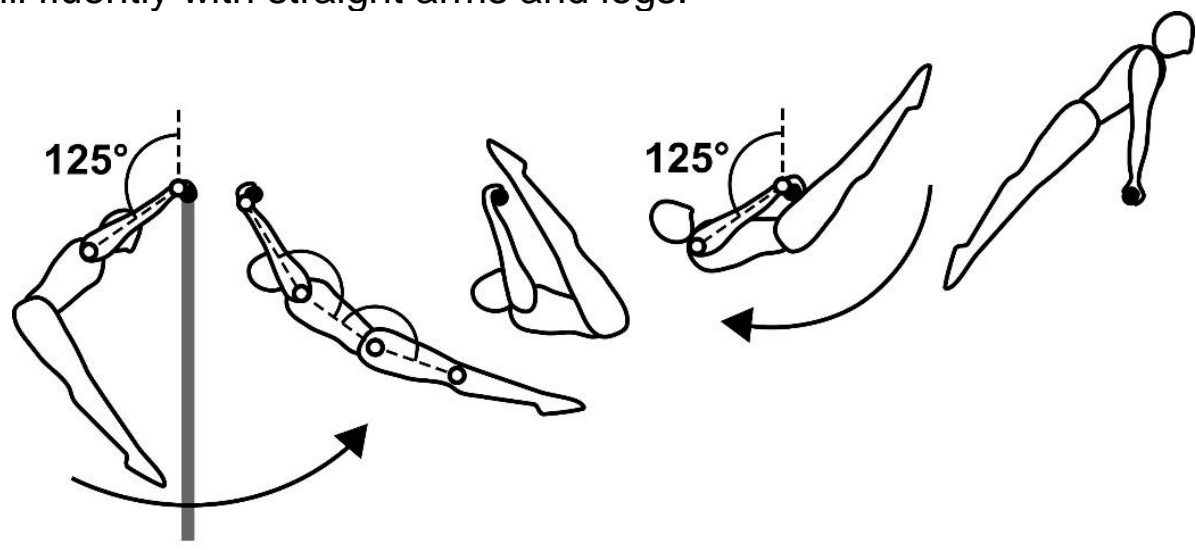
A
B
C
D
E

Figure 1. The upstart performed on a low horizontal bar, with the arm, hip and shoulder angle defined. 
Despite being a fundamental skill the upstart is often difficult to learn as it requires coordination of the actions at the hip and shoulder with the rotational position of the body. In a previous study on the upstart (Bevan \& Corser, 1969) cited by Hay (1985), the timing of the hip flexion in relation to the whole-body rotation (Figure 1C) was considered to be a "crucial element" of the successful performance of the skill. Hiley \& Yeadon (2014) used a computer simulation model to determine the solution space associated with this action, by varying the timing of the hip flexion and the duration of the kipping action (hip and shoulder extension). For an elite male gymnast the solution space was relatively large with a successful upstart possible with a range of timings. However, for a gymnast who was not as strong, the solution space was relatively small, indicating that timing of the actions was indeed crucial. It was also demonstrated that a weaker gymnast, such as a novice gymnast, would have to adapt the technique (joint angle time histories) to be less extended at the front of the swing in order to be successful.

In gymnastics many skills are taught through progressions, where a progression is a sequence of skills that progressively builds to the desired skill (Readhead, 1987, Irwin, Hanton \& Kerwin, 2005). The recommended specificity of the skills within the progression (Readhead, 1987, Irwin \& Kerwin, 2005) must be to build the required patterns of movement to acquire the final skill. Irwin \& Kerwin (2005) determined the most appropriate progression skills, based on the similarity of (inter-limb) coordination, to learn a longswing on the horizontal bar (where the gymnast swings through $360^{\circ}$ from handstand to handstand above the bar with an extended body). This would suggest that as a learner is coached the technique and coordination should move towards the desired movement patterns. If the exercises and augmented (coaching) feedback are based around producing the desired final movement patterns, this might be expected. It has been shown that coaches predominantly use knowledge of performance (information about the movement quality/characteristics) when providing augmented feedback (Fishman \& Tobey, 1978), and this is "particularly beneficial when there are specific movement requirements as in gymnastics" (Magill, 2010).

However, Williams et al. (2016) investigated the (inter-limb) coordination of the functional phase of the longswing as novices learnt to swing over an eight-week period. The functional phase was defined as the mechanically important actions performed as the gymnast swings beneath the bar. Despite the participants being coached it was found that the successful novice gymnasts, those that could swing from handstand to handstand, did not use a coordination pattern (measured by continuous relative phase (CRP) between the shoulder and hip) that was similar to expert performers. In other words, to be successful at the task alternative coordination patterns had been adopted. These findings were interpreted to imply that coaches "should strongly consider the appropriateness of encouraging (or inferring) development towards a kinematic "gold standard" during motor learning" (Williams et al., 2016). This runs contrary to the previous research of Fishman \& Tobey (1978) and Magill (2010) referred to earlier. Busquets et al. (2013) studied how the longswing technique and coordination changed across age groups. They found that the placement of actions, at the shoulder and hip (i.e. where they are performed in the swing) and coordination followed a temporal pattern with expertise. That is, the first key action/event in the circle/swing and its coordination were acquired first followed by the next key action/event and so on. This suggests that the skill is built in stages with the technique and coordination for each stage acquired concurrently. Busquets et al. (2013) analysed the skill in relation to the position of the key actions within the swing (i.e. where in the swing), whereas Williams et al. (2016) looked at the interaction (coordination) between the shoulder and hip 
during a defined period of the swing using continuous relative phase (van Emmerick et al., 2013).

Much research has been carried out on the relationship between variability of technique and coordination with expertise (e.g. Busquets et al., 2016; Hiley, Zuevsky \& Yeadon, 2013; Williams et al., 2016). Hiley et al. (2013) found that elite gymnasts had very consistent joint angle time histories during the mechanically important phases of the longswing, but they were more variable through the upper region of the circle compared to less elite gymnasts. Hiley \& Yeadon (2016) subsequently demonstrated the functional nature of this greater variability showing that gymnasts were making feedback corrections through the upper part of the circle based on a strategy for controlling the whole body angular velocity from circle to circle. All of the actions throughout the upstart are mechanically important and therefore, it might be expected that novices will be more variable in technique and coordination compared to experts and may show a reduction in variability of both as they progress. Williams et al. (2016), also found that elite gymnasts had more consistent coordination patterns than novices, but did not find a systematic reduction in variability for the novices over the eight-week training period.

The aim of the present study is to determine how technique and coordination change as novice gymnasts learn to upstart. It is hypothesised that both technique and coordination will become more like an expert as learning progresses and that the gymnasts will become more extended at the front of the swing as their competence increases. It is also hypothesised that variability in both technique and coordination will decrease as learning progresses.

\section{METHODS}

\section{Participants}

Eight (7 male, 1 female) recreational gymnasts (mean \pm SD: age $=20.3 \pm 1.5$ years, mass $=73.3 \pm 9.8 \mathrm{~kg}$, height $=1.78 \pm 0.09 \mathrm{~m}$ ) from the university gymnastics club and one elite (male) gymnast (age $=19.9$ years, mass $=62.0 \mathrm{~kg}$, height $=1.75$ ) who competed internationally, gave informed consent to participate in the study which was approved by the university's ethics committee. The primary inclusion criterion for the eight recreational gymnasts who participated was to have never successfully completed an upstart. All eight participants were free from injury and prepared to engage in the training programme. The participants were assessed for strength in terms of number of chin-ups (mean \pm SD: $8 \pm 4$ ) and leg lifts $(4 \pm 3)$ they could perform from a full hang from a bar. All participants were able to perform at least one of each exercise.

\section{Procedure}

Prior to initial testing the eight participants were familiarised with the upstart (graphics sequence and demonstration) but received no specific coaching. After initial testing participants attended two coached training sessions (20 to 30 minutes, groups of 2 to 3 participants) each week for a total of four months. All training sessions were led by a qualified gymnastics coach experienced in teaching the upstart. During each training session, in addition to drills and exercises with direction from the coach to improve strength and technique, at least ten upstarts were attempted without any physical assistance from the coach. At each testing session the number of successful upstarts performed out of ten attempts was assessed by the coach for each participant. An upstart was considered successful if the final support position above the bar could be achieved. Testing sessions were conducted at monthly intervals with kinematic 
data collected at the initial and final sessions. The elite male gymnast, who competed internationally, only attended one testing session.

\section{Data collection}

Kinematic data were collected using an eight-camera motion capture system (Vicon MX T20) operating at $300 \mathrm{~Hz}$ (Figure 2). The volume (2 m x $3 \mathrm{~m} \times 4 \mathrm{~m}$ ) centred at the bar (1.9 m high) was wand calibrated prior to data collection. A total of 9 spherical reflective markers, $25 \mathrm{~mm}$ in diameter, were attached to the lateral side of the head, toe, ankle, knee, hip, shoulder, elbow and wrist of the right side of the body. Additionally, one marker was placed at the centre of the bar. Participants were asked to attempt 10 upstarts (i.e. data were collected for all 10 trials), each starting from a box adjusted in height such that the arms of the participant were horizontal, with the toes level with the end of the box (Figure 2).
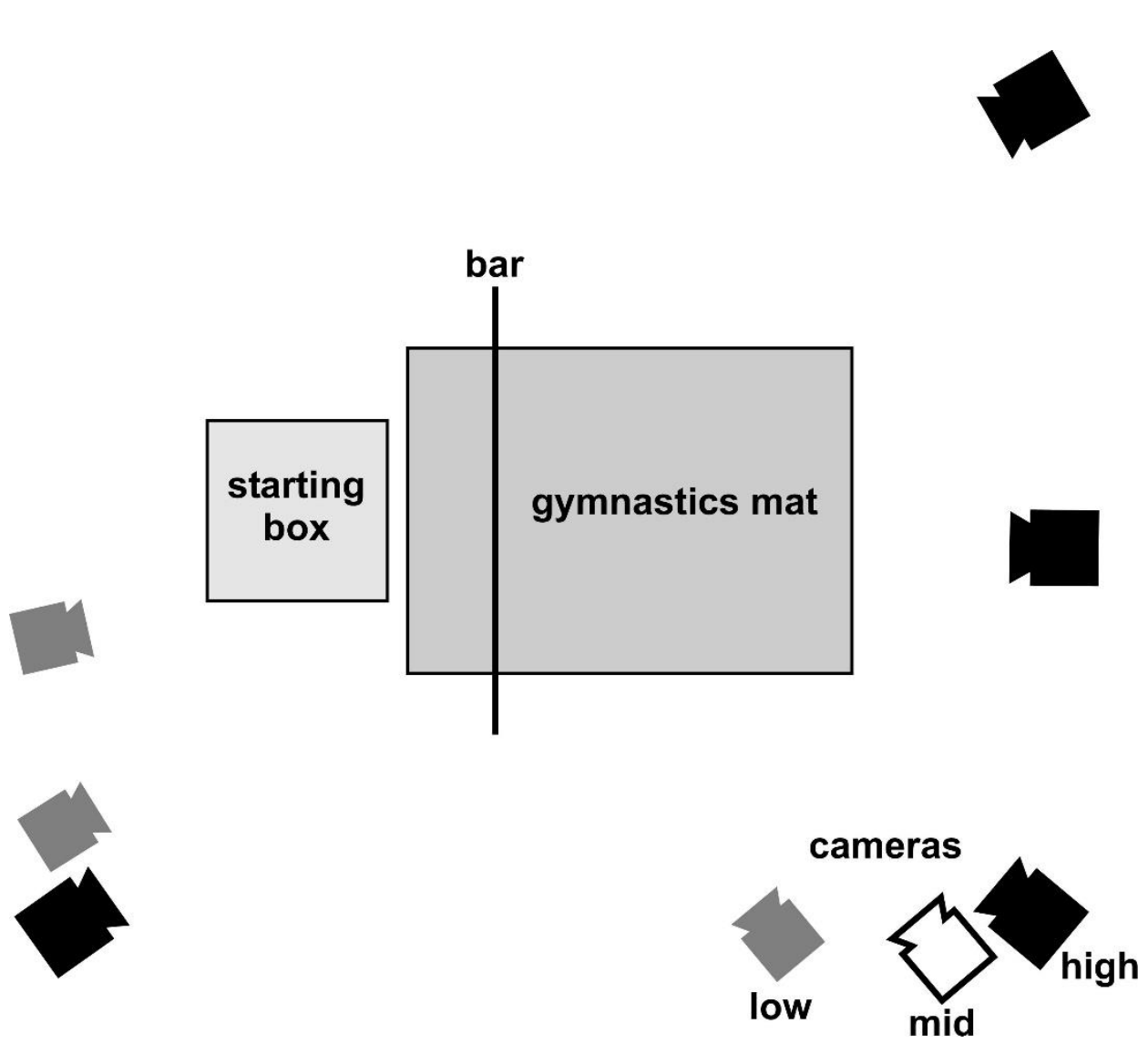

Figure 2. Schematic of data collection set up, including cameras set at low (2.5 m, grey), mid (3.5 m, white) and high ( $4.5 \mathrm{~m}$, black) level.

\section{Data processing}

Three-dimensional marker coordinates were reconstructed and filtered using a Butterworth low pass filter with a cut off frequency of $10 \mathrm{~Hz}$ (Winter, 1990). Arm, shoulder and hip angles in the sagittal plane (Figure 1) were determined from the reconstructed joint centres. The arm angle was used as the orientation angle of the gymnast and was defined as the angle made by the line joining the wrist to the shoulder and the upward vertical (Figure 1). For each trial the minimum arm angle was recorded. For successful trials an angle of $0^{\circ}$ was recorded indicating that the gymnast had reached the support position above the bar. 
Continuous relative phase (CRP) between the shoulder and hip was calculated using the method described by Williams et al. (2016). The portion of the upstart from the first time the arm passed through $125^{\circ}$ (Figure 1A) and the second time (Figure 1D) was chosen for the analysis. This region was chosen since it avoided any small differences in orientation at the start of a trial, incorporated the important actions (swing, Figure 1A-B, body extension, Figure 1B, hip flexion, Figure 1C, and kipping, Figure 1C-D), and was achieved by all participants in all trials. The shoulder and hip angles and angular velocities were time and amplitude normalised as described previously (Williams et al., 2016; Hamill et al., 1999; van Emmerik, et al., 2013) and the phase planes plotted for each joint (angular velocity versus angle). The phase angle was calculated as the arctangent of the phase plane slope for each joint. The CRP between the joints was calculated as the difference between the phase angle of the shoulder and the hip (van Emmerik et al., 2013). A CRP angle of $0^{\circ}$ indicated an in-phase coupling and an angle of $180^{\circ}$ indicated an anti-phase coupling (Kelso, 1984).

The variability in the participants' technique was calculated as the point by point mean standard deviation of the time normalised joint angle time histories over the 10 trials. The coordination variability was calculated as the point by point mean standard deviation of the CRP for the 10 trials.

\section{Data analysis}

The root mean squared (RMS) difference between the average hip and shoulder joint angle time histories of each participant and the elite gymnast were used to determine how close the novices were to the expert technique. The same procedure was carried out for the CRP data to determine how close the novices' coordination was to the expert. All data were assessed for normality using the Shapiro-Wilk test (Field, 2009) and were found to be normally distributed. Paired t-tests (one tailed) were carried out to determine whether there had been an improvement in technique or coordination between testing sessions one and five (initial and final) in comparison to the expert. Further t-tests were carried out on the body extension at the front of the swing (shoulder plus hip angle) and the joint angle time history and CRP variability data between sessions one and five. Effect sizes were calculated using Cohen's d, and were considered as being trivial (0-0.19), small (0.20-0.49), medium (0.50-0.79) and large (0.80 and greater) according to Cohen (1992).

\section{RESULTS}

After four months of coaching and training half of the participants were successful at performing an upstart $80 \%$ or more of the time, the remainder were largely unsuccessful (Table 1). All participants improved the minimum arm angle achieved from session one to five $(p<0.001, d=2.7)$, where $0^{\circ}$ corresponds to the arm vertically above the bar (Figure 1). There was only a small improvement in the participants' strength with the final average number of chin-ups remaining the same as the initial testing $(8 \pm 4)$ and the average number of leg lifts increasing by $2(6 \pm 3)$.

The RMS difference between the participants' technique and elite gymnast's technique (joint angle time histories) and coordination (CRP) was significantly smaller $(p=0.018, d=1.2$ and $p<0.001, d=2.8$, respectively) when comparing sessions one and five (Table 2, Figure 3). The participants' technique and coordination became more like the elite gymnast from sessions one to five. As training progressed the participants became significantly $(p=0.008, d=1.4)$ more extended at the front of the swing (Table 2). 
Table 1. The number of successful (S) upstarts out of 10 for each session along with the average ( \pm standard deviation) minimum arm angle (MAA) achieved in sessions one and five

\begin{tabular}{cccccccc}
\hline & & \multicolumn{7}{c}{ Session } \\
Subject & $\mathbf{S}$ & $\mathbf{1}$ & $\mathbf{2}$ & $\mathbf{3}$ & $\mathbf{4}$ & \multicolumn{1}{c}{$\mathbf{5}$} \\
& & MAA & $\mathbf{S}$ & $\mathbf{S}$ & $\mathbf{S}$ & $\mathbf{S}$ & MAA \\
\hline 1 & 0 & $112^{\circ}\left( \pm 10^{\circ}\right)$ & 0 & 0 & 0 & 0 & $50^{\circ}\left( \pm 11^{\circ}\right)$ \\
2 & 0 & $115^{\circ}\left( \pm 6^{\circ}\right)$ & 0 & 0 & 0 & 1 & $27^{\circ}\left( \pm 22^{\circ}\right)$ \\
3 & 0 & $78^{\circ}\left( \pm 3^{\circ}\right)$ & 0 & 0 & 0 & 1 & $30^{\circ}\left( \pm 19^{\circ}\right)$ \\
4 & 0 & $113^{\circ}\left( \pm 6^{\circ}\right)$ & 0 & 0 & 0 & 0 & $60^{\circ}\left( \pm 25^{\circ}\right)$ \\
5 & 0 & $92^{\circ}\left( \pm 3^{\circ}\right)$ & 0 & 2 & 7 & 8 & $4^{\circ}\left( \pm 8^{\circ}\right)$ \\
6 & 0 & $67^{\circ}\left( \pm 13^{\circ}\right)$ & 8 & 9 & 9 & 10 & $0^{\circ}\left( \pm 0^{\circ}\right)$ \\
7 & 1 & $58^{\circ}\left( \pm 30^{\circ}\right)$ & 10 & 9 & 9 & 10 & $0^{\circ}\left( \pm 0^{\circ}\right)$ \\
8 & 0 & $68^{\circ}\left( \pm 7^{\circ}\right)$ & 4 & 10 & 8 & 10 & $0^{\circ}\left( \pm 0^{\circ}\right)$ \\
Average & $\mathbf{0}$ & $\mathbf{8} 7^{\circ}$ & $\mathbf{3}$ & $\mathbf{4}$ & $\mathbf{4}$ & $\mathbf{5}$ & $\mathbf{2 1 ^ { \circ }}$ \\
\hline
\end{tabular}

Table 2. The RMS difference between participants and elite gymnast for technique (mean joint angle time histories) and coordination (CRP shoulder/hip) along with maximum extension angle at the front of the swing

\begin{tabular}{|c|c|c|c|c|c|c|}
\hline \multirow{3}{*}{ Subject } & \multicolumn{6}{|c|}{ Session } \\
\hline & 1 & 5 & 1 & 5 & 1 & 5 \\
\hline & Technique & Technique & CRP & CRP & Max Ext. & Max Ext. \\
\hline 1 & $31^{\circ}$ & $29^{\circ}$ & $36^{\circ}$ & $11^{\circ}$ & $286^{\circ}$ & $314^{\circ}$ \\
\hline 2 & $23^{\circ}$ & $20^{\circ}$ & $38^{\circ}$ & $17^{\circ}$ & $311^{\circ}$ & $328^{\circ}$ \\
\hline 3 & $22^{\circ}$ & $16^{\circ}$ & $17^{\circ}$ & $7^{\circ}$ & $336^{\circ}$ & $353^{\circ}$ \\
\hline 4 & $20^{\circ}$ & $21^{\circ}$ & $21^{\circ}$ & $13^{\circ}$ & $313^{\circ}$ & $336^{\circ}$ \\
\hline 5 & $29^{\circ}$ & $7^{\circ}$ & $53^{\circ}$ & $6^{\circ}$ & $281^{\circ}$ & $347^{\circ}$ \\
\hline 6 & $23^{\circ}$ & $16^{\circ}$ & $47^{\circ}$ & $8^{\circ}$ & $324^{\circ}$ & $329^{\circ}$ \\
\hline 7 & $17^{\circ}$ & $15^{\circ}$ & $30^{\circ}$ & $8^{\circ}$ & $307^{\circ}$ & $314^{\circ}$ \\
\hline 8 & $31^{\circ}$ & $16^{\circ}$ & $47^{\circ}$ & $7^{\circ}$ & $309^{\circ}$ & $328^{\circ}$ \\
\hline Average & $24^{\circ}$ & $18^{\circ}$ & $36^{\circ}$ & $9^{\circ}$ & $308^{\circ}$ & $331^{\circ}$ \\
\hline Elite gymnast & & & & & & $346^{\circ}$ \\
\hline
\end{tabular}

Table 3. The variability (mean point to point standard deviation) of the participants' and elite gymnast's technique (joint angle time histories) and coordination (CRP)

\begin{tabular}{|c|c|c|c|c|}
\hline Subject & $\begin{array}{c}1 \\
\text { Technique }\end{array}$ & $\begin{array}{c}\text { Sessior } \\
5 \\
\text { Technique }\end{array}$ & $\begin{array}{c}1 \\
\text { CRP }\end{array}$ & $\begin{array}{c}5 \\
\text { CRP }\end{array}$ \\
\hline 1 & $13^{\circ}$ & $4^{\circ}$ & $34^{\circ}$ & $11^{\circ}$ \\
\hline 2 & $7^{\circ}$ & $4^{\circ}$ & $24^{\circ}$ & $8^{\circ}$ \\
\hline 3 & $6^{\circ}$ & $5^{\circ}$ & $12^{\circ}$ & $7^{\circ}$ \\
\hline 4 & $6^{\circ}$ & $7^{\circ}$ & $22^{\circ}$ & $13^{\circ}$ \\
\hline 5 & $7^{\circ}$ & $6^{\circ}$ & $21^{\circ}$ & $6^{\circ}$ \\
\hline 6 & $5^{\circ}$ & $4^{\circ}$ & $10^{\circ}$ & $8^{\circ}$ \\
\hline 7 & $9^{\circ}$ & $6^{\circ}$ & $22^{\circ}$ & $8^{\circ}$ \\
\hline 8 & $5^{\circ}$ & $4^{\circ}$ & $15^{\circ}$ & $5^{\circ}$ \\
\hline Average & $7^{\circ}$ & $5^{\circ}$ & $20^{\circ}$ & $8^{\circ}$ \\
\hline Elite gymnast & & $3^{\circ}$ & & $5^{\circ}$ \\
\hline
\end{tabular}


The participants became significantly more consistent in terms of their technique $(p=0.031, d=1.1)$ and coordination $(p<0.001, d=4.8)$ with training (Table 3$)$. In both measures the elite gymnast was more consistent than the novices.
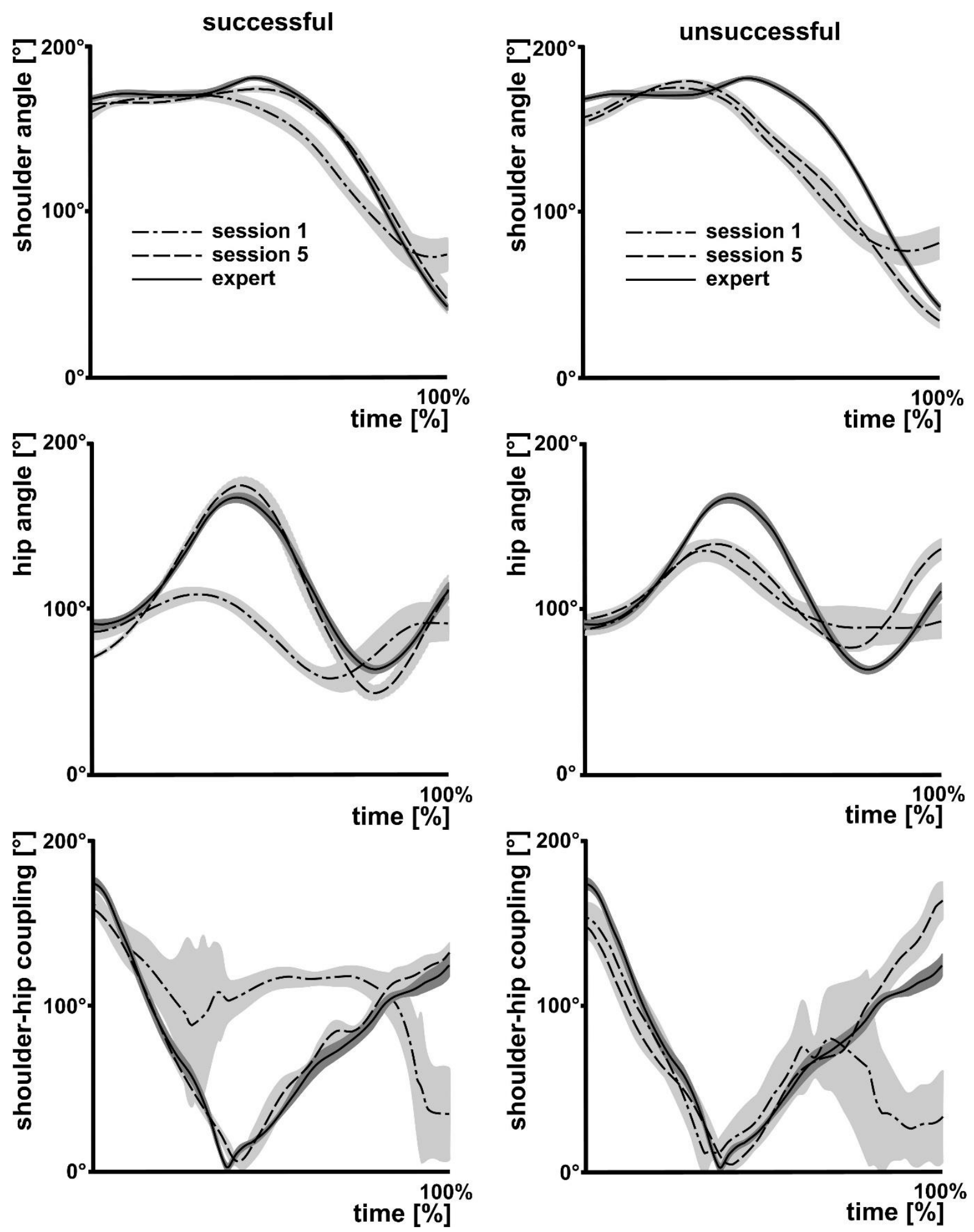

Figure 3. Average joint angle time histories and continuous relative phase between the shoulder and hip (shaded areas \pm one standard deviation) for one successful and one unsuccessful novice compared to the expert for sessions one and five. 


\section{DISCUSSION}

The aim of the study was to investigate whether technique and coordination of novice gymnasts became more like those of an expert as the learning of the upstart progressed. All eight novices showed an improvement in performance over the 4month training period (Table 1) and both technique (joint angle time histories) and coordination (coupling of the shoulder and hip angles) became more similar to the expert gymnast (Table 2). It has previously been shown that the solution space for novice gymnasts attempting the upstart can be relatively small (Hiley and Yeadon, 2014). The learning process involves developing inter-limb coordination (Newell, 1985), where the various components of the movement are pieced together (Newell, 1985) but also where they are combined with the environment, i.e. performing the actions at the correct points in the swing. It is the combination of these requirements with physiological and environmental constraints that define a successful solution space (Newell, 1986). If the novices do not have the requisite physical characteristics, such as strength or flexibility, the number of possible successful techniques will be smaller. If the actions at the shoulder and hip have to be performed at the correct time in order to be successful it would therefore follow that the novices would tend towards this technique and become more consistent as their success rate increased.

It was hypothesised that the novice gymnasts would become more consistent in the technique and coordination used as learning progressed. During learning, it might be expected that increased levels of variability will be observed as participants "discover" new strategies and techniques (Chow, Davids, Button, \& Rein, 2008; Cohen \& Sternad, 2009). As the solution space is discovered, the level of variability will likely decrease (Cohen \& Sternad, 2009; Wilson et al., 2008). Whether this decrease in variability continues or whether a "U" shaped relationship is found with increasing skill level (Wilson et al., 2008) appears to depend on the task (Cohen \& Sternad, 2009; Broderick \& Newell, 1999; Hiley et al., 2013; Wilson et al., 2008). In the present study there was a significant decrease in the variability for the novices in both terms of technique and coordination (Table 3, Figure 3). Despite potentially having a large solution space (Hiley \& Yeadon, 2014), the elite gymnast was less variable than the novices in both of these measures (Table 3, Figure 3).

The conclusions of previous research on coordination are in conflict with each other (Williams et al., 2016; Busquets et al., 2013). A possible issue of using CRP in this situation is that it reports the coupling between two specified segments/joint angles. This means that it does not explicitly consider where this coupling occurs within the swing. In terms of the longswing, the timing of the actions within the swing have been demonstrated to be very important, particularly in relation to generating energy and therefore to the amplitude of the swing (Yeadon \& Hiley, 2000; Servez et al., 2009). If the correct coupling is used but at the wrong time, the swing amplitude may not increase. Indeed, Williams et al. (2016) stated it may not be the coupling of the shoulder and hip that is as important as the biomechanical constraints of the task. The explanation was that in previous studies the hip actions of novices had become more like the expert, but the contribution of the shoulder was limited (Williams et al., 2015a, 2015b), and therefore lead to different shoulder-hip coordination patterns. As Busquets et al. (2013) suggest, it is important that the components of the technique are built initially. Therefore, care must be taken when using various methods of analysis in order that the results are meaningful and can be interpreted in terms of what the participants are doing.

In the case of the upstart, the coaching literature (Bevan \& Corser, 1969; Fukushima \& Russell, 1980; Readhead, 1987), previous research (Hiley \& Yeadon, 
2013, 2014, Yamasaki et al., 2010) and the present research indicate that the relative timing of the actions at the shoulder and hip are important. However, it is only when these are performed at the correct place within the swing that a successful upstart can be performed. Therefore, it is encouraging that the unsuccessful participants were learning to coordinate the shoulder and hip actions, but they had perhaps not yet acquired the timing of these actions within the swing, in order to be successful. To investigate whether this might be the case, the CRP between the arm angle (effectively the orientation angle) and the hip angle for sessions one and five were calculated (Figure 4). Both the successful and unsuccessful participants, on average, initially deviated from the coupling of the elite gymnast. By session five the successful participants, on average, had a coupling that was much closer to the elite gymnast, indicating that the coordination between the hip action and the swing was closer to the expert. When looking at the joint angle time histories (Figure 3) in combination with the arm-hip coupling, the period that the successful novices are closer to the expert's coordination than the unsuccessful novices is from maximum hip extension, through minimum hip flexion and the following extension, as might be expected from the previous literature (Hay, 1985; Hiley \& Yeadon, 2014). The successful novices are able to time the bringing of the feet to the bar (and the subsequent kip) with the swing better than the unsuccessful novices. In other words, they coordinate their technique with the swing better than their less successful colleagues. Despite the weakest of the eight novices, in terms of number of leg lifts and chin-ups, being in the unsuccessful group, hip and shoulder strength did not appear as a limiting factor (7.0 \pm 5.0 vs $9.7 \pm 1.0$, p $=0.319$ and $5.0 \pm 3.6$ vs $7.7 \pm 3.0, p=0.281$, respectively) for the two groups, based on independent measures t-tests. That is, there were equivalently strong participants in each group, therefore other factors such as co-ordinating technique with the swing will have had more influence on the respective success rates of the two groups.
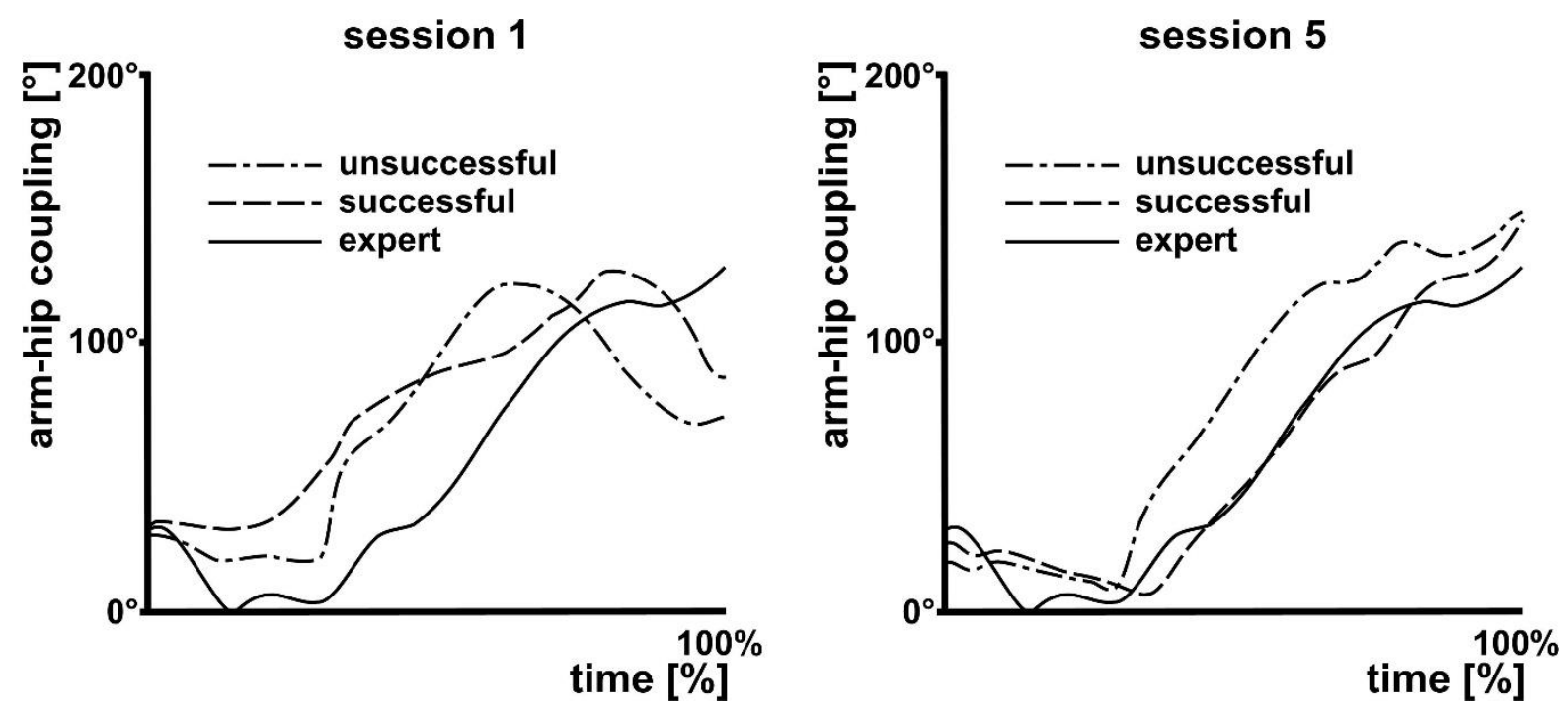

Figure 4. Average continuous relative phase between the arm and hip angles for the successful and unsuccessful novices compared to the expert for sessions one and five

\section{CONCLUSION}

When learning to upstart it appears that the mechanics of the skill determines success and that inter-limb coordination is a by-product of acquiring the "right" technique, i.e. joint angles are co-ordinated with the swing and are therefore coordinated with each other. Predescu (2005) defined the "right" or "correct" 
gymnastics technique as satisfying the following: forms the basis for future skills, is safe, biomechanically proven, serves long term targets without being changed, follows the FIG code of points (Fédération Internationale de Gymnastique, 2017). In the case of the upstart the solution space is small, and so the range of "right" techniques is limited, particularly for the learner who may not have the physical characteristics of an elite gymnast. In order to be successful at the upstart the learner must acquire the "correct" technique (and coordination) and therefore technique and coordination approach that of the elite performer as learning progresses. In the case of the longswing the solution space is somewhat less constrained, since energy can be added to the system with varying contributions from the shoulder and hip joint actions (Williams et al., 2015b). However, as the longswing is a fundamental skill that is used in the development of more advanced skills (Busquets et al., 2011; Hiley \& Yeadon, 2016; Irwin \& Kerwin, 2005), coaches do not view success as merely achieving a longswing. If swinging from handstand to handstand is no longer the goal of the longswing and a new set of mechanical constraints is imposed by the coach, it is to be expected that a learner's technique will approach that of an expert (Busquets et al. 2013). Since gymnastics coaches use progressions (Readhead, 1987; Irwin \& Kerwin, $2005)$ to teach skills, this suggests that the "correct" technique and long-term goals are prioritised over speed of achieving success (Busquets et al., 2013). Therefore, care should be taken when designing learning studies that the outcome measure does not cloud the real-world process and that coaches are not discouraged from teaching the "correct" technique.

\section{ACKNOWLEDGEMENTS}

The authors would like to thank the participants for their time and commitment to the study.

\section{REFERENCES}

1. Bevan, R., \& Corser T. (1969). Biomechanical study of gymnastic movements. The Gymnast, March, 30.

2. Broderick, M.P., \& Newell, K.M. (1999). Coordination patterns in ball bouncing as a function of skill. Journal of Motor Behavior, 31, 165-188.

3. Busquets, A., Marina, M., \& Angulo-Barroso, R.M. (2013). Changes in motor strategies across age performing a longswing on the high bar. Research Quarterly for Exercise and Sport, 84, 353-362.

4. Busquets, A., Marina, M., Davids, K., \& Angulo-Barroso, R.M. (2016). Differing roles of functional movement variability as experience increases in gymnastics. Journal of Sports Science and Medicine, 15, 268-276.

5. Busquets, A., Marina, M., Irurtia, A., Ranz, D., \& Angulo-Barroso, R.M. (2011). High bar swing performance in novice adults; Effect of practice and talent. Research Quarterly for Exercise and Sport, 82, 1-9.

6. Chow, J.Y., Davids, K., Button, C., \& Rein, R. (2008). Dynamics of movement patterning in learning a multiarticular action. Motor Control, 12, 219-240.

7. Cohen, J. (1992). A power primer. Psychological Bulletin, 112, 155-159.

8. Cohen, R.G., \& Sternad, D. (2009). Variability in motor learning: relocating, channeling and reducing noise. Experimental Brain Research, 193, 69-83.

9. Fédération Internationale de Gymnastique. (2017). Code of Points. Moutier, Switzerland: F.I.G.

10. Field A. P. (2009). Discovering statistics using SPSS. London, England: SAGE. 
11. Fishman, S., \& Tobey, C. (1978). Augmented feedback. In W.G. Anderson \& G. Barrette (Eds.), What's going on in gym: Descriptive studies of physical education classes. Motor Skills: Theory Into Practice (Monograph I), pp. 51-62.

12. Fukushima, S., \& Russell, W. (1980). Men's gymnastics. London: Faber \& Faber.

13. Hamill, J., van Emmerik, R.E.A., Heiderscheit, B.C., \& Li, L. (1999). A dynamical systems approach to lower extremity running injuries. Clinical Biomechanics, 14, 297-308.

14. Hay, J.G. (1985). The biomechanics of sports technique, third edition. New Jersey: Prentice Hall.

15. Hiley M.J., \& Yeadon, M.R. (2016). The role of functional variability in a whole body co-ordinated movement: application to high bar giant circles. Human Movement Science, 49, 95-103.

16. Hiley, M.J., \& Yeadon, M.R. (2013). Investigating optimal technique in a noisy environment: application to the upstart on uneven bars. Human Movement Science, 32, $181-191$.

17. Hiley, M.J., \& Yeadon, M.R. (2014). Determining the solution space for a coordinated whole body movement in a noisy environment: application to the upstart in gymnastics. Journal of Applied Biomechanics, 30, 508-513.

18. Hiley, M.J., Zuevsky, V.V., \& Yeadon, M.R. (2013). Is skilled technique characterised by high or low variability? - An analysis of high bar giant circles. Human Movement Science, 32, 171-180.

19. Irwin, G., Hanton, S., \& Kerwin, D.G. (2005). The conceptual process of skill progression development in artistic gymnastics. Journal of sports sciences, 23, 1089-1099.

20. Irwin, G, \& Kerwin, D.G. (2005). Biomechanical similarities of progressions for the longswing on high bar. Sports Biomechanics, 4, 163-178.

21. Kelso, J.A.S. (1984). Phase transition and critical behavior in human bimanual coordination. American Journal of Physiology, 15, 1000-1004.

22. Magill, R.A. (2010). Motor learning and control: Concepts and applications. McGraw Hill, New York.

23. Newell, K.M. (1985). Coordination, control and skill. In R.B. Wilberg \& I.M. Franks (Eds.), Differing perspectives in motor learning, memory, and control. Amsterdam: Elsevier Science.

24. Newell, K.M. (1986). Constraints on the development of coordination. In M.G. Wade \& H.T.A. Whiting (Eds.), Motor development in children: Aspects of coordination and control. Dordrecht: Martinus Nijhoff.

25. Predescu, G. (2005). Practical advice about how to choose the right technique. Gymcraft, 17, 7-8.

26. Readhead, L. (1987). Men's gymnastics coaching manual. Huddersfield: Springfield Books.

27. Sevrez, V., Berton, E., Rao, G., \& Bootsma, R.J. (2009). Regulation of pendulum length as a control mechanism. Human Movement Science, 28, 250-262.

28. van Emmerik, R.E.A., Hamill, J., \& McDermott, W.J. (2005). Variability and coordinative function in human gait. Quest, 57, 102-123.

29. van Emmerik, R.E.A., Miller, R.H., \& Hamill, J. (2013). Dynamical systems methods for the analysis of movement coordination. In G. Robertson, G. Caldwell, J. Hamill \& G. Kamen (Eds.), Research methods in biomechanics (2nd ed.). Champagne, IL: Human Kinetics.

30. Williams, G.K.R., Irwin, G., Kerwin, D.G., \& Newell, K.M. (2015a). Changes in joint kinetics during learning the longswing on high bar. Journal of Sports Sciences, 33, 29-38. 
31. Williams, G.K.R., Irwin, G., Kerwin, D.G., \& Newell, K.M. (2015b). Biomechanical energetic processes during learning the longswing on high bar. Journal of Sports Sciences, 33, 1376-1387.

32. Williams, G.K.R., Irwin, G., Kerwin, D.G., Hamill, J., van Emmerik, R.E.A., \& Newell, K.M. (2016). Coordination as a function of skill level in the gymnastics longswing. Journal of Sports Sciences, 34, 429-439.

33. Wilson, C., Simpson, S.E., van Emmerik, R.A., \& Hamill, J. (2008). Coordination variability and skill development in expert triple jumpers. Sports Biomechanics, 7, 29.

34. Winter, D. (1990). Biomechanics and motor control of human movement. WileyInterscience: Toranto-Ontario.

35. Yamasaki, T., Gotoh, K., \& Xin, X. (2010). Optimality of a kip performance on the high bar: An example of skilled goal-directed whole body movement. Human Movement Science, 29, 464-482.

36. Yeadon, M.R., \& Hiley, M.J. (2000). The mechanics of the backward giant circle on the high bar. Human Movement Science, 19, 153-173. 